\title{
Publisher Correction: Farming with crops and rocks to address global climate, food and soil security
}

David J. Beerling (D), Jonathan R. Leake (D), Stephen P. Long (D), Julie D. Scholes, Jurriaan Ton (D), Paul N. Nelson (D), Michael Bird (D), Euripides Kantzas, Lyla L. Taylor (D), Binoy Sarkar (D), Mike Kelland, Evan DeLucia, Ilsa Kantola, Christoph Müller (D), Greg H. Rau and James Hansen

Correction to: Nature Plants https://doi.org/10.1038/s41477-018-0108-y, published online 19 February 2018.

In the version of this Perspective originally published, 'acidification' was incorrectly spelt as 'adification' in Fig. 4. This has now been corrected.

Published online: 25 May 2018

https://doi.org/10.1038/s41477-018-0162-5 